\title{
Embryology of myelomeningocele and anencephaly
}

\author{
Mark S. Dias, M.D., and Michael Partington, M.D. \\ Department of Neurological Surgery, Penn State Milton S. Hershey Medical Center, Penn State \\ University College of Medicine, Hershey, Pennsylvania; and Department of Neurological Surgery, \\ Gillette Children's Hospital, St. Paul, Minnesota
}

\begin{abstract}
The authors review current views on of the embryogenesis of the neural tube defects (NTDs) myelomeningocele and anencephaly. In this context, the following four approaches to the study of NTDs are discussed: normal morphogenesis and timing of early human neural development from conception to the ascent of the conus medullaris; mechanical and molecular biology of neural tube closure derived from experimental and animal models; morphological and biomechanical features of the NTDs myelomeningocele and anencephaly; and the experimental evidence for the importance of both genetic and environmental influences on human NTDs. Although considerable insight into both normal neural tube closure and the factor(s) by which this process may be disrupted has been reported in recent years, the exact mechanism(s) by which human myelomeningoceles and anencephaly arise remain elusive.
\end{abstract}

\author{
KEY WORDS • spina bifida • myelomeningocele $\bullet$ neural tube defect $\bullet$ embryology $\bullet$ \\ genetics - folate
}

Myelomeningoceles, encephaloceles, and other NTDs are genetically complex malformations that are likely etiologically, morphogenetically, molecularly, and genetically heterogeneous. We review four approaches to study the embryology of NTDs: 1) normal morphogenesis of the early neural plate and tube; 2) molecular biology of normal neuroepithelial formation and neural tube closure; 3) experimental approaches to nutritional and enzymatic manipulations, particularly those involved in folate and methionine/homocysteine metabolism; and 4) genetic models of NTDs (primarily in mice and rats). Each of these approaches has shed considerable light on various aspects of normal and abnormal early neural development, although the exact causes of human NTDs remain elusive.

\section{NORMAL EARLY HUMAN DEVELOPMENT}

Early embryonic development has been previously reviewed $d^{13,14}$ and contains the primary references; in the interest of brevity, these references have been eliminated in the present report. During the first 2 weeks after fertiliza-

Abbreviations used in this paper: $\mathrm{BMP}=$ bone morphogenetic protein; $\mathrm{CAM}=$ cell adhesion molecule; $\mathrm{CCM}=$ caudal cell mass; $\mathrm{DLHP}=$ dorsolateral hingepoint; $\mathrm{MHP}=$ median $\mathrm{HP} ; \mathrm{NTD}=$ neural tube defect; SCM = split cord malformation. tion (postovulatory Days 1-13), the human embryo undergoes a number of cell divisions and cellular rearrangements that ultimately form a blastocyst containing a twolayered embryo suspended between the amnionic and yolk sacs (Fig. 1). By postovulatory Day 4, cells on the dorsal surface of the embryo, adjacent to the amnionic cavity, form the epiblast, whereas cells on the anterior surface, adjacent to the yolk sac, form the hypoblast. By postovulatory Day 13, the embryo thickens cranially to form the prochordal plate, the first morphological feature of craniocaudal orientation.

The primitive streak first develops on postovulatory Day 13 at the caudal end of the embryo and elongates cranially over the next 3 days (Fig. 2 upper). It reaches its full length by postovulatory Day 16 and occupies the midline in the caudal half of the human embryo. The primitive streak thereafter begins to regress, becoming shorter and moving back toward the caudal pole of the embryo. As the primitive streak develops, epiblast cells migrate toward the primitive streak and invaginate through a midline trough (the primitive groove) that runs the length of the primitive streak (Fig. 2 upper). Prospective endodermal cells are the first to ingress, displacing the underlying hypoblast cells laterally and forming the definitive endoderm (which will give rise to the lining of the respiratory 


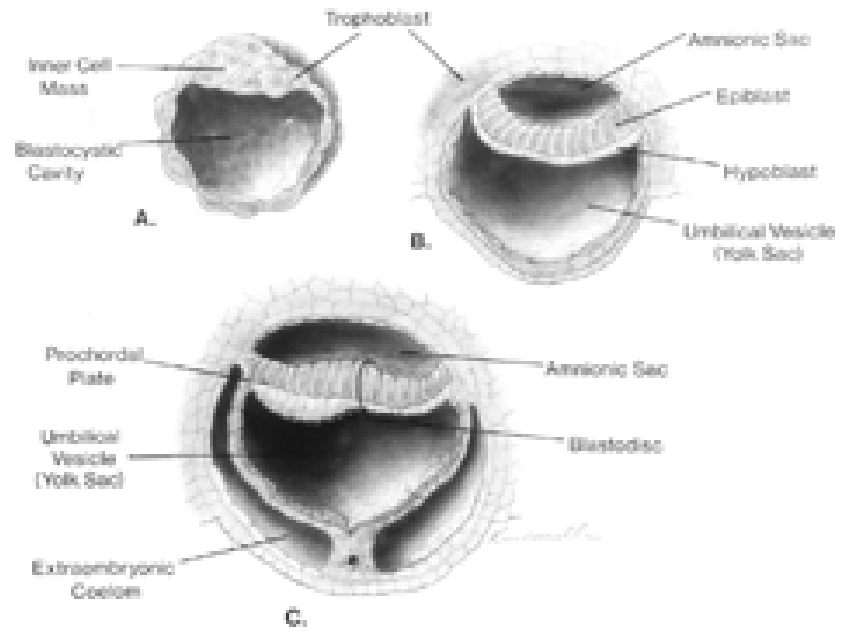

Fig. 1. Midsagittal illustrations showing development of the blastocyst. A: Continued proliferation of cells produces a sphere containing a blastocystic cavity surrounded by an eccentrically located inner cell mass and a surrounding ring of trophoblast cells. B: The inner cell mass develops further into a two-layered structure, the blastodisc, containing the epiblast adjacent to the amnionic cavity and the hypoblast adjacent to the yolk sac. C: With further development, the blastodisc thickens cranially to form the prochordal plate.

and gastrointestinal systems). Later, as the streak regresses, prospective mesodermal cells ingress through the primitive streak between the epiblast and the newly formed endoderm to form the definitive mesoderm (which will give rise to mesenchymal cells of the body wall and limbs, the somites, and the kidney). The remaining epiblast cells spread out to replace the cells that have ingressed through the primitive groove and form the ectoderm (both neuroectoderm and surface ectoderm). Embryonic endo-, meso-, and ectoderm are thus all derived from the epiblast. This process, referred to as gastrulation, transforms the embryo from a two-layered structure containing an epi- and hypoblast into a three-layered structure containing ecto-, meso-, and endoderm.

The Hensen node, a specialized structure located at the cranial end of the primitive streak, serves a special role as the organizer of the embryo. As the streak elongates, prospective endodermal cells migrate through the primitive pit (in the center of the Hensen node). As the streak regresses, prospective notochordal cells begin to invaginate through the Hensen node and are laid down in the midline between the overlying neuroectoderm and underlying endoderm as the notochordal process (Fig. 2 lower).

\section{Localization of Prospective Neuroectoderm}

In recent fate-mapping studies ${ }^{49}$ in chick embryos, investigators have localized prospective neuroectoderm to an area of the epiblast that surrounds and flanks the Hensen node and the cranial half of the primitive streak (Fig. 3 ). Results of earlier mapping studies ${ }^{56}$ suggested that the prospective neuroectoderm is organized in a linear, craniocaudal sequence, so that prospective forebrain cells are located more cranially than prospective midbrain cells. In more recent studies, however, a different organization
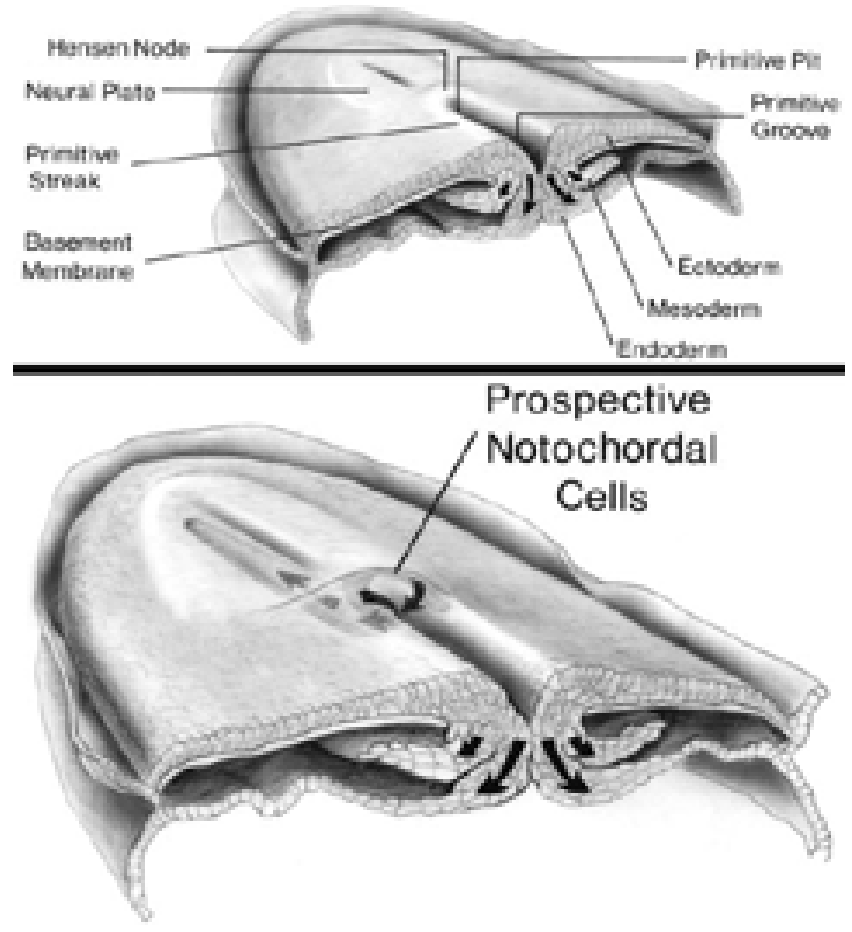

Fig. 2. Normal human gastrulation. Upper: Prospective endoand mesodermal cells of the epiblast migrate toward the primitive streak and ingress (arrows) through the primitive groove to become the definitive endoderm and mesoderm. Lower: Prospective notochordal cells in the cranial margin of the Hensen node will ingress through the primitive pit (arrows) during primitive streak regression to become the notochordal process.

is suggested. Instead of contributing to a single neuraxial level, each region of the neuroepithelium contributes to multiple neuraxial levels. For example, marking the most cranial regions of the prospective neuroectoderm results in a strip of label that extends through all craniocaudal subdivisions of the neuraxis from forebrain to spinal cord; marking more caudal levels results in similar strips that, although beginning at more caudal levels, extend caudally through all subsequent levels of the neuraxis. ${ }^{49}$

\section{Regression of the Primitive Streak and Formation of the Notochord}

In the human, the notochordal process begins to form on postovulatory Day 16 (Fig. 4). To what extent does the notochordal process extend cranially from the Hensen node and to what extent does it elongate caudally by addition of cells to its caudal end from the regressing Hensen node? In the chick, the notochordal process grows largely by the latter mechanism. ${ }^{56}$ In mammals, analysis of the available evidence suggests that the situation is much more complex and may involve both mechanisms. ${ }^{60}$ The mechanism of notochord elongation in humans is unknown.

The notochordal process consists of a cord of cells radially arranged around a central lumen called the notochordal canal (Fig. 5). The notochordal canal is continuous dorsally with the amnionic cavity through the primitive pit. The notochordal process continues to elon- 


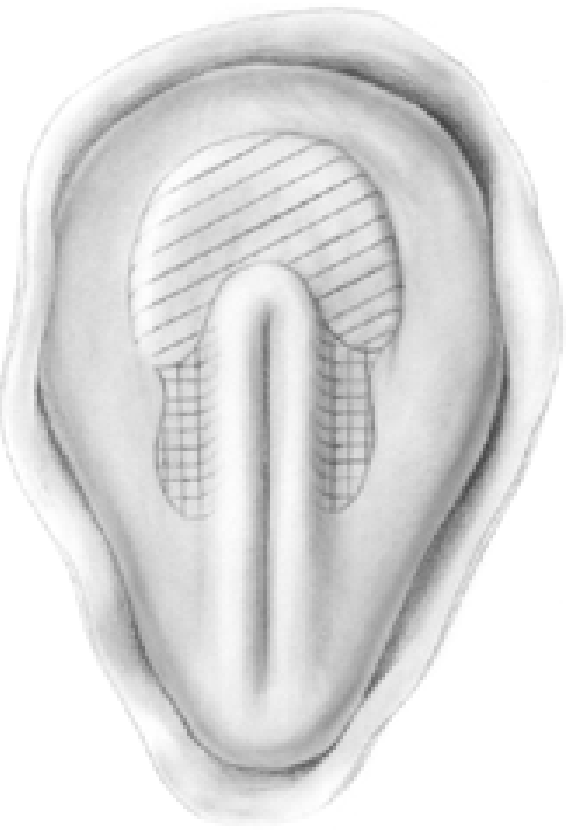

Fig. 3. Location of prospective neuroepithelium. Seen here is a dorsal view of an avian embryo during gastrulation. The striped region illustrates localization by earlier mapping studies involving carbon particles; hatched area illustrates additional caudal areas demonstrated by more recent mapping studies using horseradish peroxidase injections and chimeric transplantation.

gate between postovulatory Days 17 and 21 . Between postovulatory Days 18 to 20 it fuses, or intercalates, with the underlying endoderm to form the notochordal plate (Fig. 5). This plate is incorporated into the roof of the yolk sac, with which the notochordal canal becomes continuous. The most caudal portion of the notochordal canal is continuous both with the amnion through the primitive pit and with the yolk sac as a result of intercalation; this communication is called the neurenteric canal. The neurenteric canal first appears on postovulatory Days 17 to 19 . By postovulatory Days 23 to 25 , the notochordal plate folds

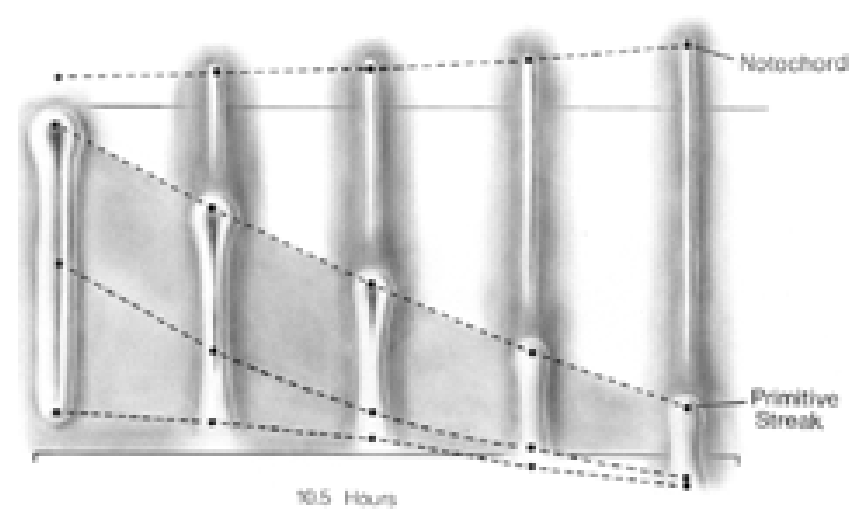

Fig. 4. Formation of the notochord in avian embryos. The notochord is formed through the addition of cells to its caudal end as the primitive streak regresses; true cranial growth of the notochord is minimal.
A. NOTOCHORDAL CANALIZATION
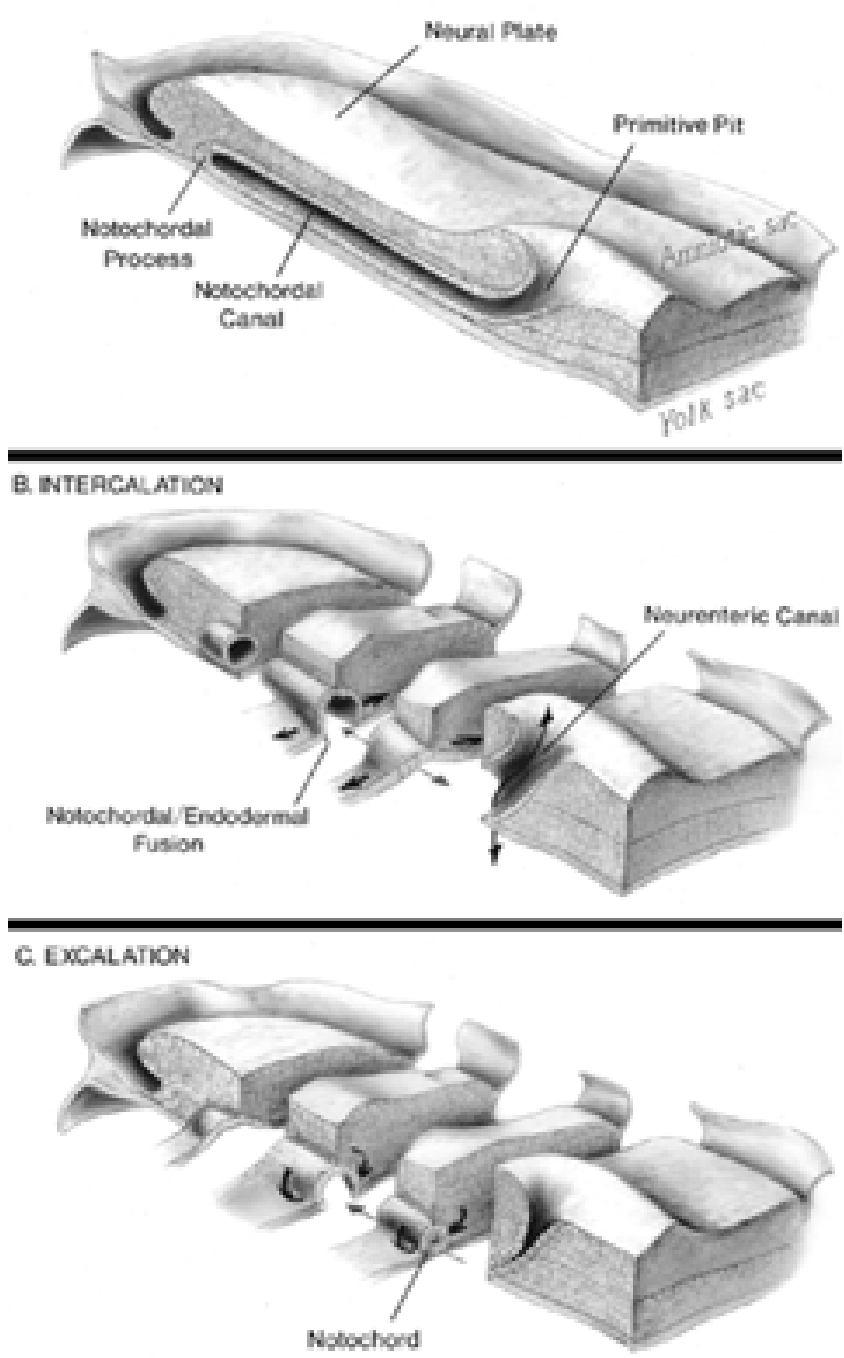

Fig. 5. Illustrations showing notochordal canalization, intercalation, and excalation. A: The notochordal process contains a central lumen (the notochordal canal), which is continuous with the amnionic cavity through the primitive pit. B: During intercalation, the canalized notochordal process fuses with the underlying endoderm; the communication of the amnion with the yolk sac forms the primitive neurenteric canal (arrows). C: During excalation, the notochord rolls up and separates from the endoderm to become the definitive notochord; the primitive neurenteric canal becomes obliterated (arrows).

dorsoventrally and separates (or excalates) from the endoderm and separates once again from the underlying endoderm (Fig. 5), obliterating the neurenteric canal and ending the communication between the amnionic and yolk sacs. Thereafter, the "true" notochord exists as a solid rod of notochordal cells.

\section{Neural Tube Formation}

The human neuroectoderm is visible by postovulatory Day 16 as a pseudostratified columnar epithelium overlying the midline notochord, and it is contiguous laterally with the surrounding squamous epithelium of the cutaneous ectoderm. A shallow midline fold, the neural 
groove, is visible on postovulatory Days 17 to 19 as a crease immediately above the midline notochord. By postovulatory Days 19 to 21 , the neural groove has deepened considerably, and neural folds develop laterally. The neural folds continue to elevate and converge toward the midline, meeting to form a closed neural tube. Closure usually involves the apposition and fusion of the cutaneous ectoderm first and then the neuroectoderm; the cutaneous ectoderm separates from the neuroectoderm (a process called dysjunction) as the neural tube closes.

In the human, the first part of the neural tube to close is the region of the caudal rhombencephalon or cranial spinal cord, usually when five pairs of somites are present. Closure of the neural tube occurs during a 4- to 6-day period. Although it was previously thought to close in a linear fashion, like a zipper extending cranially and caudally from the point of initial closure, both observations of human NTDs and experimental manipulations in mice suggest that neurulation appears to involve several waves of closure along the craniocaudal neuraxis. ${ }^{25,26,64}$ The cranial neural tube closes from the coordinated interaction of at least four waves of discontinuous neural tube closure (Fig. 6). The spinal cord closes in a linear manner from a caudal wave of neurulation that extends from the point of initial contact at the cranial end of the spinal cord to the posterior neuropore.

The caudal neuropore closes during Stage 12 (postovulatory Days 25-27). At the time the caudal neuropore closes, approximately 25 somites have formed, but the caudal neuropore is located below the last visible somite. Therefore, the site of closure can only be estimated by measuring the space between the last visible somite and the caudal neuropore and calculating the number of somites that would subsequently form in this space. Using this method, the site of closure has been estimated to be opposite somites $30 / 31,{ }^{43}$ which corresponds to both a spinal ganglion and a vertebral level of S-2.44 It therefore appears that, in the human, the majority of the spinal cord (as far caudal as S-2) forms by primary neurulation and that the terminal filum and perhaps the lower sacral spinal cord form by secondary neurulation.

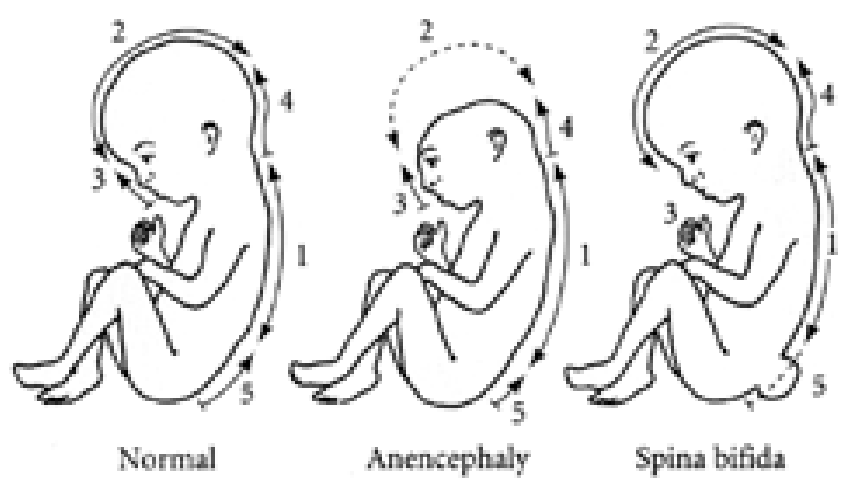

Fig. 6. Depiction of various waves of neural tube closure in human embryos. There are thought to be at least five waves of closure in normal human embryogenesis. Anencephaly is thought to represent failure of Wave 2, myelomeningocele a failure at the junction of Waves 4 and 5 (representing the junction of primary and secondary neurulation). From Gilbert SF, 2003.

\section{Formation of the Neural Crest}

Neural crest cells in the human, mouse, and rat embryo are thought to arise from the neural tube at the junction between the neural folds and adjacent surface ectoderm; in humans, however, a simultaneous origin for some neural crest cells from the adjacent surface ectoderm cannot be excluded. The neural crest in the human embryo first develops on postovulatory Day 19 to 21 during and before neural fold fusion, and continues from the closed neural tube at least until postovulatory Day 32, well after the neural folds have fused. More caudal neural crest cells arise only after neural tube closure. A similar sequence has been described in the rat. ${ }^{61}$

Spinal cord neural crest cells undergo terminal differentiation into a bewildering variety of cell types, including the melanocytes of the body wall and limbs, the Schwann cells investing the peripheral nerves, the dura mater of the spinal cord, and the dorsal root and autonomic ganglion cells of the spinal nerves. In addition, these cells give rise to the adrenal medulla. In both avian and mammallian (and presumably human) embryos, trunk neural crest cells choose either a dorsal or a ventral migratory pathway shortly after they leave the neural tube. Neural crest cells that follow the dorsal, or "subepidermal migratory," pathway will form the melanocytes of the skin, whereas those that follow the "ventral migratory pathway" will form the remaining neural crest derivatives. The neural crest cells in the ventral migratory pathway advance between the neural tube and adjacent somites, and they traverse the rostral half of the sclerotomal portion of the somite. Some of the ventral neural crest cells remain near the neural tube forms and become dorsal root ganglion cells, whereas others advance farther ventrally to become sympathetic ganglion and adrenal cells.

\section{Secondary Neurulation}

With closure of the caudal neuropore on postovulatory Days 25 to 27, the entire nervous system is covered with skin and more caudal neural development occurs by secondary neurulation. The remnants of the primitive streak have regressed to the caudal embryonic pole and form a mass of pluripotent cells called the CCM. By postovulatory Days 25 to 27 , the CCM extends from the posterior neuropore to the cloacal membrane. The cells of the CCM are multipotent and, at least in the chick embryo, give rise to the neural tube and vertebrae caudal to S-2, but not the hindgut that is instead derived from endoderm, nor the posterior notochord that is derived from a posterior notochordal region located immediately anterior to the CCM and underlying the primary neural tube.

The mechanism of secondary neurulation is species specific (Fig. 7). In the chick embryo, secondary neurulation results in the formation of a medullary cord from the dorsal cells of the CCM. Within the medullary cord, an outer layer of tightly packed cells surrounds an inner cluster of more loosely arranged cells. Cavitation between the two cell groups creates multiple tubules with the outer cells surrounding a central lumen, within which are the inner cells. The inner cells are eventually lost, and the outer cells then surround multiple empty lumina. Multiple smaller lumina coalesce to form larger cavities; eventual- 

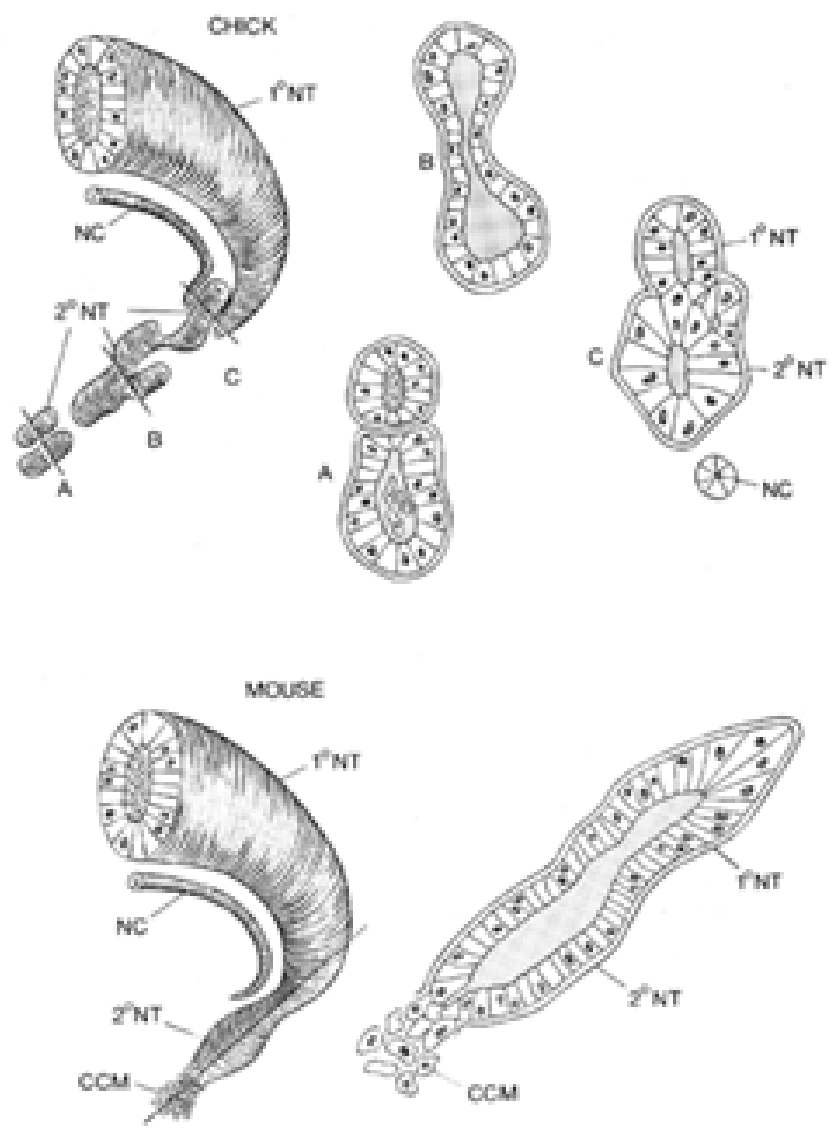

Fig. 7. Secondary neurulation. Upper illustration depicts secondary neurulation in avian embryos. A: The medullary cord consists of multiple lumina, each surrounded by an outer layer of tightly packed, radially oriented cells and containing an inner group of more loosely packed cells. B: Adjacent cords coalesce to form larger aggregates; simultaneously, the inner cells are lost. Eventually a single structure is formed, having a single lumen that is not yet in direct communication with the lumen formed by primary neurulation. C: Later, the neural tube formed by secondary neurulation $\left(2^{\circ} \mathrm{NT}\right)$ fuses with that formed from primary neurulation $\left(1^{\circ} \mathrm{NT}\right)$; at this point, the lumina of the two neural tubes communicate directly. Lower illustration depicts secondary neurulation in mouse embryos. A medullary rosette is composed of cells radially arranged about an empty central lumen. The lumen is always in communication with the central canal formed by primary neurulation. Growth of the secondary neural tube occurs by additional cavitation of the secondary lumen and by recruiting additional cells from the CCM. $\mathrm{NC}=$ notochord.

ly a single lumen is formed and is surrounded by the outer cell group. This secondary neural tube fuses with the neural tube formed during primary neurulation in an area called the overlap zone, within which the primary neural tube is located dorsally and the secondary neural tube ventrally.

Secondary neurulation in the mouse begins with the formation of a medullary rosette, a cluster of CCM cells radially arranged about a central lumen formed by cavitation. The cells of the medullary rosette are thought to be the homolog of the outer cell group in the chick embryo; the inner cell group seen in the chick is not present in the mouse. Caudal growth of the secondary neural tube occurs by additional cavitation of the medullary rosette and recruitment of additional cells from the CCM.

Secondary neurulation in the mouse and chick differ in at least two respects. First, the secondary neural tube in the mouse is always directly continuous with the primary neural tube and develops caudally from the posterior neuropore; in contrast, the secondary neural tube in the chick develops independently and only later fuses with the primary neural tube. Second, the lumen of the secondary neural tube in the mouse is single and is always continuous with that of the primary neural tube; in contrast, multiple lumina are initially formed in the chick and only later communicate with one another and with the lumen of the primary neural tube.

The issue of whether secondary neurulation in humans more closely resembles that in the chick or mouse is unresolved. According to Müller and O'Rahilly, ${ }^{43}$ human secondary neurulation more closely resembles that in the mouse; in their study, the neural cord was continuous with the primary neural tube, a single lumen was present and continuous with the central canal of the primary neural tube, and no overlap zone was observed. In contrast, Lemire $^{34}$ and Bolli ${ }^{4}$ have described multiple independent secondary tubes associated with separate lumina and no discernible connection with one another or the primary neural tube as occurs in the chick.

\section{Occlusion of the Spinal Neurocele}

During and immediately after neural tube closure (between approximately postovulatory Days 23 to 32 ), the central lumen of the neural tube portion that will form the spinal cord becomes temporarily occluded. The lateral walls of the neural tube in this region become apposed and the lumen is obliterated. Occlusion of the neurocele begins cranial to the first pair of somites, extends as far caudal as the ninth somite, and involves approximately $60 \%$ of the neuraxis. During occlusion of the neurocele, the neural tube cranial to the point of occlusion expands rapidly for two reasons: 1) because of the neural tube growth; and 2) because of ventricular system expansion. This has led several authors to suggest that neurocele occlusion may play an important role in the initial expansion of the brain and ventricular system..$^{32,48}$ The closure of the cranial neuropore and the occlusion of the caudal neural tube isolate the cranial ventricular system from the environment and establish a closed, fluid-filled space. Once established, the isolated ventricular system is subjected to an intraluminal pressure that provides a driving force for brain enlargement. If the intra- and extraluminal pressures are equalized by cannulating the cranial neural tube lumen with a hollow glass rod during the period of rapid brain enlargement, brain expansion is significantly impaired; the neural tube is collapsed and folded and its walls contain fewer cells. A failure to maintain this driving pressure in patients with open neural tube defects has been proposed as a mechanism for the genesis of the Chiari malformation. ${ }^{37}$

\section{Ascent of the Conus Medullaris}

Beginning approximately on postovulatory Days 43 to 48 and continuing into later fetal development and even perhaps the first months of postnatal life, the position of 
the conus medullaris changes its position with respect to the adjacent vertebral column, in what is termed the "ascent of the conus medullaris" (Fig. 8). As a result, the conus medullaris comes to lie opposite progressively more cranial vertebrae. This ascent involves at least two mechanisms. Before postovulatory Day 54 the ascent is generally attributed to a process termed retrogressive differentiation in which the caudal neural tube loses much of its diameter and becomes thinner, fails to develop a distinct mantle zone, exhibits only a thin, rudimentary marginal zone, and generally appears less well developed than it did at earlier embryonic stages. After postovulatory Day 54 , the ascent is due primarily to a disparity between the growth rates of the vertebral column and the spinal cord.

The ascent of the conus medullaris during pre- and postnatal life has been examined by several investigators. $2,18,30,68,69$ Most of the ascent occurs prenatally, between 8 and 25 weeks' gestation (Fig. 8); between Weeks 25 and 40 , the rate of ascent slows. ${ }^{2}$ Initial studies in human cadavers conducted by Barson ${ }^{1,2}$ and others ${ }^{30}$ have suggested that the conus medullaris lies opposite the L2-3 disc space at birth and ascends farther to its "adult" level opposite or cranial to the L1-2 disc space by 2 months postnatally. The authors of more recent studies involving spinal ultrasonography and magnetic resonance imaging in newborn infants have suggested that the conus medullaris has achieved its adult position opposite the L1-2 disc space at the time of birth and does not ascend any farther after this time. ${ }^{18,68,69}$ Although as many as $2 \%$ of healthy individuals have a more caudally positioned conus at or below the L-3 vertebral body ${ }^{46}$ a conus that lies below the mid-body of L-2 is generally accepted by many as radiographic evidence of spinal cord tethering.

\section{MORPHOGENESIS OF NEURAL TUBE CLOSURE}

Neurulation is a complex morphogenetic process composed of several interdependent events, all of which overlap temporally to some degree. These processes include the following: 1) shaping of the neuroepithelium to form a neural plate; 2) bending of the neural plate, first in the midline neural groove and later along the lateral edges of the neural tube, resulting in elevation and apposition of the neural folds in the midline; and 3) fusion of the neural folds to close the neural tube. The mechanisms of normal neurulation are reviewed here; the interested reader is referred to the monograph by Schoenwolf and Smith ${ }^{50}$ for a more comprehensive discussion.

\section{Shaping of the Neural Plate}

The neuroepithelium undergoes a change in shape during which it thickens apicodorsally, narrows mediolaterally, and lengthens craniocaudally. These changes convert the neuroepithelium from a relatively flat, oval structure to one that is more narrow and more elongated (the neural plate). The first visible change in the neuroepithelium is an elongation of individual neuroepithelial cells from a cuboidal to a columnar shape. This cell shape change is caused largely by a reorganization of intracellular longitudinally (or paraxially) oriented microtubules. These microtubules are abundant in neuroepithelial cells of
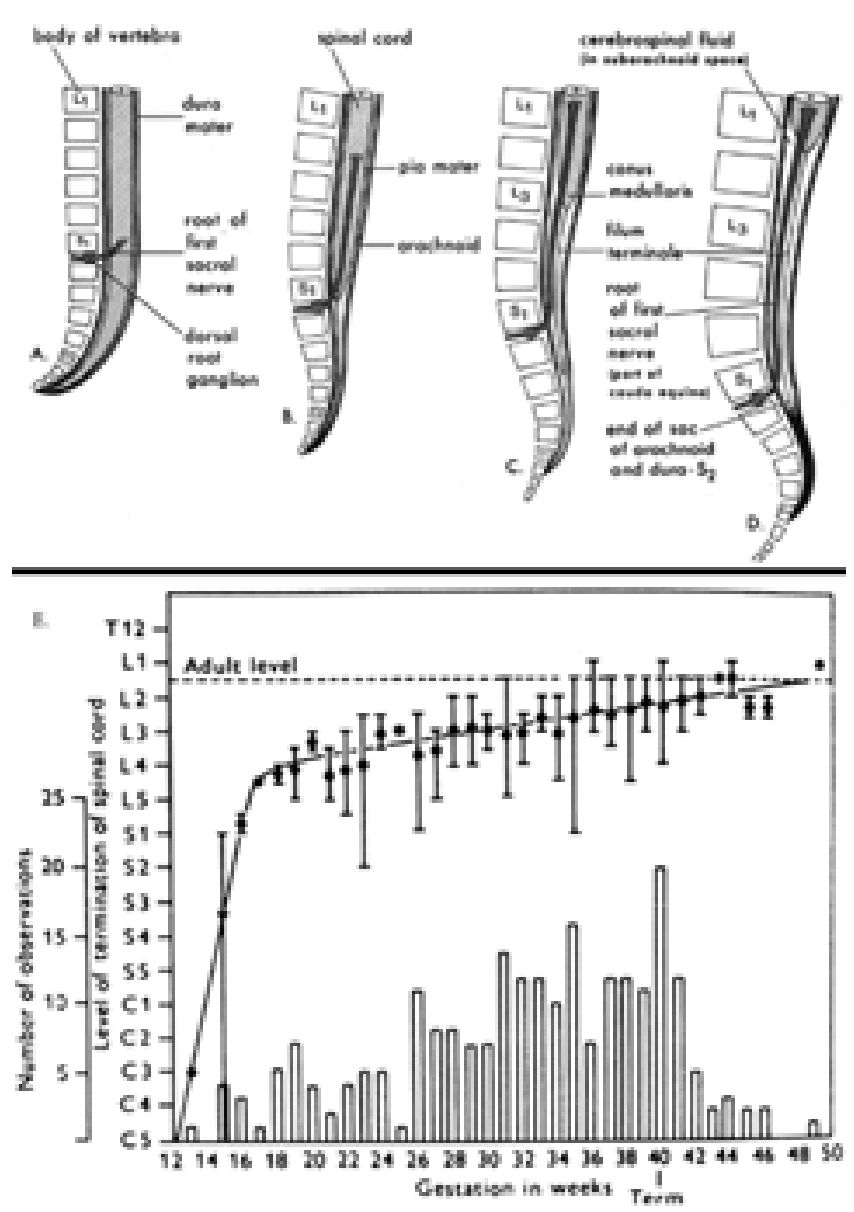

Fig. 8. Ascent of the conus medullaris. A-D: Illustrations demonstrating progressive ascent of the conus medullaris during embryogenesis and the immediate postnatal period. (A, 8 weeks' gestation; B, 24 weeks' gestation; C, newborn; and D, adulthood. (From Moore KL, 1982). E: Vertebral level of termination of the conus medullaris during fetal and early postnatal life. Adapted from Chatkupt, Chatkupt, and Johnson, 1993.

many species, and neuroepithelium from embryos exposed to agents that depolymerize microtubules does not fully elongate. Although important, microtubules are likely not the only forces contributing to neuroepithelial cell elongation. Other mechanisms that may be important in neuroepithelial cell elongation include differential cellcell adhesion and cortical "tractoring."

\section{Bending of the Neural Plate}

In standard embryology texts neurulation is equated with neural plate bending, which converts the flat neural plate into a round neural tube. Neural plate bending in chick embryos has been extensively studied and involves several discrete steps (Fig. 9). The first step involves cellshape changes in midline neural plate cells overlying the notochord; these cells are transformed from a columnar to a wedge shape and form an MHP, or neural groove. The neural folds on either side of the MHP elevate to form a characteristic V shape (Fig. 9). A little later, similar cellshape changes occur in discrete, bilaterally paired regions of the dorsolateral neural tube and are associated with the 
(A) Formation of neural folds

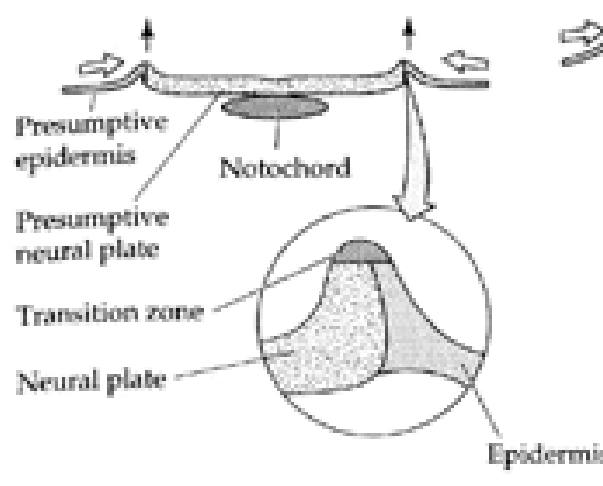

(B) Elevation of neural folds

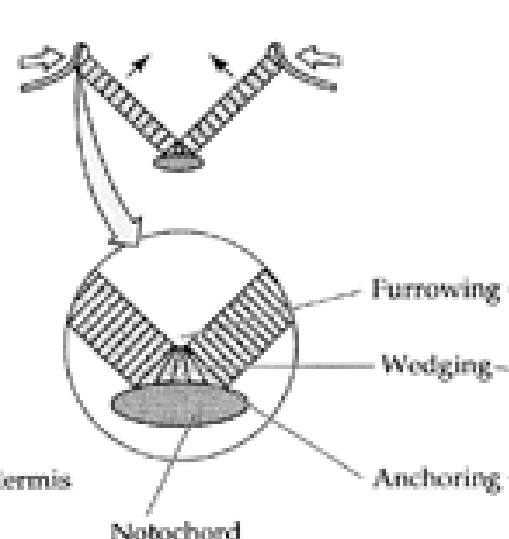

(C)

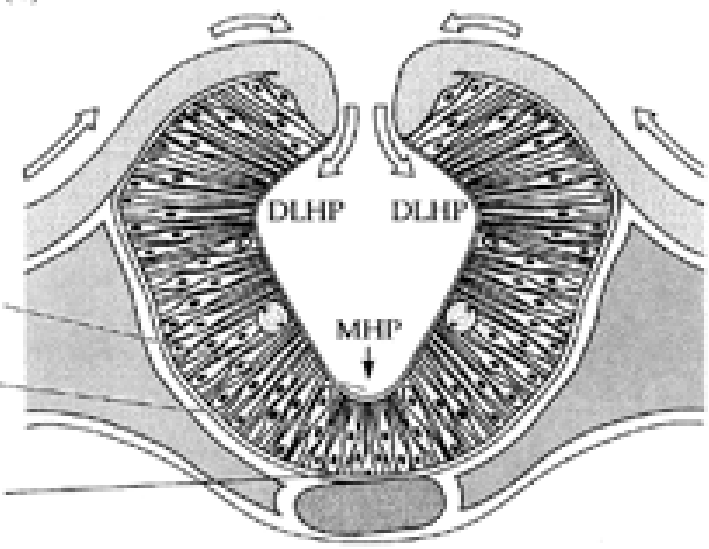

Fig. 9. Morphogenetics and biomechanics of neural plate bending. A: Formation of neural folds from neuroepithelium and adjacent cutaneous ectoderm (presumptive epidermis). The transition zone will give rise to the neural crest cells and their derivatives. B: Formation of the MHP or neural groove, and elevation of the neural folds. Note the wedging of the midline neuroepithelial cells immediately dorsal to the notochord (inset). C: Formation of the DLHP and convergence of the neural folds in preparation for neural fold fusion (From Gilbert SF, 1997).

formation of the DLHPs, around which the neural folds converge toward the midline. Finally, the converging neural folds meet in preparation for neural fold fusion. Similar morphological changes have been observed in mammallian embryos but have not been as well characterized as in the chick.

In traditional theories three fundamental concepts have been espoused: 1) ". . . all forces for neurulation are intrinsic to the neuroepithelium," 2) ". . . neurulation is driven by changes in the shape of neuroepithelial cells;" and 3) "... [ [the] forces for cell shape changes are generated by the cytoskeleton of neuroepithelial cells." ${ }^{50}$ Each of these concepts, however, has been challenged by more recent experimental evidence, and more recent theories have emphasized the importance of forces both intrinsic and extrinsic to the neuroepithelium during neural plate bending.

In 1885 Roux first proposed that neurulation was a process intrinsic to the neuroepithelium; he demonstrated that the neural plate could roll up into a tube when cultured in isolation. The neural tubes in these experiments, however, roll up sooner than expected, do not undergo the aforementioned characteristic shaping movements, and often roll up backwards (that is, with the apical side of the neuroepithelium on the outside of the neural tube). Schoenwolf and Smith ${ }^{50}$ have argued that the bending movements of isolated neuroepithelium are nonspecific and do not represent neurulation.

More recent experimental evidence suggests that forces extrinsic to the neuroepithelium may play an important role in promoting neural tube bending. The medial convergence of the adjacent cutaneous ectoderm, for example, may push the neural folds together toward the midline. Expansion of mesodermal extracellular matrix or accumulation of mesodermal cells beneath the neuroepithelium may elevate the overlying neural folds. Finally, the active elongation of the notochord and/or the so-called notoplate (that is, the notochord combined with the overlying MHP cells of the neural tube) may stretch the neu- ral tube craniocaudally and, by simple mechanical deformation, draw the neural folds together (a process referred to as Eulerian buckling).

The second traditional concept, that neural plate bending is driven by changes in neuroepithelial cell shape, was first proposed by His in 1894, who suggested that if cells in a flat sheet were to become wedge shaped, either through apical constriction or basal expansion, the sheet would fold into a tube. Wedging appears to be restricted to the regions of the hingepoints in chick embryos; consequently, the neural plate bends at these specific points. Although MHP wedging may assist neural plate bending, experimental evidence suggests that it is neither necessary nor sufficient for neurulation to occur. ${ }^{50}$ Neurulation can occur even when MHP wedging is prevented by irradiating or removing the notochord. Moreover, if the neural plate is experimentally isolated from more lateral tissues, MHP cells still undergo wedging, but neurulation fails to occur. It has been suggested that, rather than driving neural plate bending, MHP wedging may direct bending toward a specific site. ${ }^{50}$ In this regard, the MHP region may provide a crease on which neural plate bending may occur. The DLHP likely plays a more important role in neural plate bending. ${ }^{50}$ In one experimental study, chick embryos treated with cytochalasin D (an agent that disrupts microfilaments) did not develop DLHP wedging; the neural folds in these embryos failed to converge about the DLHP, and these embryos consequently were dysraphic. A failure of neural fold convergence around the DLHP region is also a common feature of many animal models of dysraphism.

The third traditional concept is that cell wedging is caused by the contraction of circumferentially oriented apical microfilaments. Analysis of a large body of observational and experimental evidence suggests an important role for apical microfilaments in neural plate bending. Apical microfilaments are present in neuroepithelial cells of a number of animal embryos and are better seen during neural plate bending, suggesting a "sliding filament" ac- 
tion. Actin and myosin are both localized to the apices of neuroepithelial cells, and the apical microfilaments bind heavy meromyosin, a component of the actin-myosin complex. When embryos are treated with agents that disrupt microfilaments, neurulation often fails to occur. Finally, calcium, a mediator of microfilament contraction, has been localized to coated vesicles in the apices of neuroepithelial cells and is released during neurulation; neural plate bending is impaired by agents that inhibit calcium release, and promoted by agents that enhance it.

Alternatively, cells could become wedge shaped through the expansion of the cell base. In the chick, changes in neuroepithelial cell shape are closely correlated with the position of the cell nucleus. During cell wedging, the nucleus is translocated toward the cell base and is associated with a prolongation of certain phases of the cell cycle. These changes in the cell cycle are induced, at least in the MHP, by the notochord. Transplanting an accessory notochord beneath a more lateral region of the neuroepithelium produces a second hingepoint over the accessory notochord with correspondingly prolonged cell cycle times. The stimulus for DLHP formation is unknown. Finally, it is not known whether changes in neuroepithelial cell cycle times are the cause or the result of changes in cell shape.

\section{Neural Fold Fusion}

Apposition and fusion of the converging neural folds is the least understood portion of neurulation. The behavior of opposing neuroepithelial cells may involve moleculemolecule, molecule-cell, or cell-cell interactions. ${ }^{19}$ At least three cellular mechanisms may contribute, alone or in combination, to neural fold fusion. They include the following: 1) interactions of cell surface glycoproteins such as glycosaminoglycans and/or CAMs; 2) interdigitation of cell surface filopodia or blebs; and 3) formation of intercellular junctions. All three of these processes may be involved at different times during neural fold fusion. Cell surface recognition may be the initial event that brings the neural folds into apposition. Interdigitating cell processes may aid further to establish connections between opposing cell surfaces. Finally, intercellular junctions may serve to establish more permanent connections between adjacent neuroepithelial cells. ${ }^{38}$

Several lines of evidence suggest an important role for cell surface glycoproteins in neural fold fusion. A carbohydrate-rich surface coat material, which stains readily with ruthinium red and lanthanum (which bind to polyvalent anions), and with horseradish peroxidase-labeled concanavalin A (which binds to terminal glycosyl and mannosyl residues), has been demonstrated on the neural folds of embryos. This surface coat material is largely composed of glycosaminoglycans (complex glycoproteins that contain multiple carbohydrate residues). Both temporal and spatial distributions of cell surface glycoproteins change during neurulation. The labeling of cell surface glycoproteins is scant in early neural groove stages, progressively increases as the neural folds elevate and converge, reaches a maximum just before neural fold fusion, and declines thereafter. Labeling initially is present along the floor and walls of the neural plate, but it moves dorsally during neural fold elevation and becomes restricted to the prospective fusion areas of the neural folds. The character of glycosaminoglycans on the neuroepithelial cell surface also changes during neurulation. Hyaluronic acid is the predominant glycosaminoglycan before neural fold fusion is complete, whereas chondroitin sulfate predominates following neural fold fusion.

Several experimental observations suggest that these cell surface glycoproteins participate in neural fold fusion. Exposing mouse embryos to agents that remove or inhibit the formation and/or function of surface-coated glycoproteins all result in neural tube defects. Finally, glycosaminoglycan expression is defective in the splotch mouse $(\mathrm{Sp} / \mathrm{Sp})$ mutant; both hyaluronic acid and chondroitin sulfate are present in approximately equal amounts in the open neural tube of affected animals, whereas hyaluronic acid predominates in the normal open neural tube and chondroitin sulfate predominates in the normal closed neural tube. ${ }^{38}$

Other cell surface molecules may also be important for neural fold fusion. In particular, the cell adhesion molecules N-CAM, E-CAM, and cadherin appear to be important for the separation of neuroectoderm from cutaneous ectoderm. Before neurulation, both prospective epidermal and neuroectodermal cells express E-CAM. As neurulation proceeds, neuroepithelial cells stop expressing E-CAM and begin expressing N-CAM and cadherin; as a result, the two tissue types no longer adhere to one another and dissociate. Amphibian embryos in which surface ectodermal cells are made to express N-CAM have difficulty separating the neural tube from the cutaneous ectoderm.

The second cellular mechanism that may contribute to neural fold fusion is the interaction of cell membrane processes. Variably described as filopodia, ruffles, or blebs, these processes have been observed on the luminal surfaces of neuroepithelial cells in amphibian, chick, and mammallian embryos. Like cell surface glycoproteins, these processes become more prominent throughout neurulation, reach a peak at approximately the time of neural fold fusion, and decline thereafter; they are most conspicuous on the luminal surfaces of the converging neural folds. The temporal appearance and spatial distribution of these filopodia suggest a role in neural fold fusion, either by aligning the converging neural folds or by drawing the apposed surfaces together.

Eventually, intercellular connections are established between neuroepithelial cells of the apposed neural folds. Neither the nature of these junctions (tight or gap) nor their function (cell adhesion or intercellular communication) are known with certainty. Much more work is needed to elucidate the roles of these intercellular junctions, as well as the importance of cell surface glycoproteins and filopodia, in promoting and maintaining neural fold fusion.

The forces underlying secondary neurulation are even less well understood than those underlying primary neurulation. In the chick, the outer cells of the medullary cord elongate during secondary neurulation to become columnar cells; these shape changes rely at least in part on microtubules, as do those that occur during primary neurulation. The forces that drive cavitation to form secondary lumina are not understood; however, at least in the chick, cavitation does not rely on hydrostatic pressure from the 
lumen of the primary neural tube because these secondary lumina form without a direct connection with the lumen of the primary neural tube. Moreover, when closure of the caudal neuropore is prevented in the chick, eliminating the hydrostatic pressure within the primary neural tube lumen, secondary neurulation occurs normally.

\section{MOLECULAR BIOLOGY OF NEURULATION}

In the past decade, greater understanding of the molecular and genetic control of early neural (and vertebral) development has been achieved; the interested reader is referred to a recent review by Dias and Schoenwolf ${ }^{16}$ for the primary references. Early embryonic development is highly controlled at the genetic level by certain regulatory genes that encode developmental regulatory proteins directly (by binding to regulatory sites on DNA) or indirectly (through inter- and intracellular signaling pathways) regulate the expression of developmental genes and their gene products, controlling the fate of cells and tissues within the embryo. This genetic control is highly conserved across species; both the expression of these regulatory genes, and the intra- and intercellular signaling mechanisms by which they exert their control, are virtually identical ranging from the fruit fly (Drosophila) to the embryos of fish, amphibians, reptiles, birds, and mammals. The same is true in humans. Many of these regulatory proteins are expressed at numerous critical moments during embryogenesis to orchestrate early tissue interactions during gastrulation and neurulation, as well as the later development of various organs. The result of these interactions is a tightly integrated and beautifully choreographed molecular dance that converts a single-celled zygote into a highly organized embryo. The molecules involved in this molecular control can be divided into two classes: signal transduction molecules and transcription factors.

\section{Signal Transduction Pathways}

Developmental regulatory genes all encode RNA or proteins that have, either directly or indirectly, a single function - that is, the regulation of DNA transcription, messenger RNA translation, or posttranslational modification of gene products. Many are involved in the transfer of information from the cell surface to the genome through signal transduction pathways. Although the specifics of each pathway are different, all signal transduction pathways use common elements. A membrane bound protein on the surface of the target cell interacts with an external ligand (usually a membrane bound or secreted factor from another cell or group of cells). The membrane bound protein on the target cell has an extracellular portion (the receptor) to which the ligand will bind, a membrane spanning region, and an intracellular portion. Receptor-ligand binding results in a conformational change in the receptor, thereby exposing or activating enzymatic sites on the intracellular portion of the molecule. Most commonly, the intracellular portion is a protein kinase of some sort, which uses adensine 5'-triphosphate to phosphorylate a second intracellular messenger or cascade of messengers. Eventually, a transcription factor is activated, binds to regulatory regions of the DNA, and initiates or modulates the expression of multiple genes.
A number of signal transduction pathways have been studied, and detailed descriptions of these can be found in Gilbert's textbook. ${ }^{23}$ The complexity within each pathway, and the opportunity for cross-communication between pathways, creates numerous ways in which these pathways can be developmentally regulated. To understand the complexity of signal transduction pathways during development, consider the interaction of two Drosophila genes hedgehog and wingless, which are expressed by cells in adjacent embryonic segments (Fig. 10). Hedgehog, a signal transduction protein that is extremely important in the development of both the spinal cord and vertebral column, is secreted from one cell and binds with the receptor patched on the surface of an adjacent cell. The binding of hedgehog to patched activates a third membrane bound protein, smoothened. Activation of smoothened sets in motion a cascade of intracellular second messengers within the second cell, eventually activating the transcription of the gene wingless and the synthesis of the wingless protein. The wingless protein is secreted from the second cell and binds to a cell surface protein frizzled on the first. This interaction activates the intracellular protein dishevelled, which then blocks the inhibiting action of Zw3kinase on $\beta$-catenin (also called armadillo), effectively activating $\beta$-catenin. The $\beta$-catenin induces the transcription of engrailed, a transcription factor that then activates the transcription of hedgehog. A positive feedback loop is thereby established between the two sets of cells, creating a distinct border between adjacent segments that have very different molecular expressions. As will be clarified, these borders are important in establishing segmentation in Drosophila as well as rostrocaudal metameric patterning in both the vertebrate nervous system and spinal column.

Transcription Factors. A second class of regulatory developmental genes are the transcription factors, molecules that bind to DNA regulatory sites and modulate the transcription of other genes. These transcription factors are often the end products of the signal transduction pathways

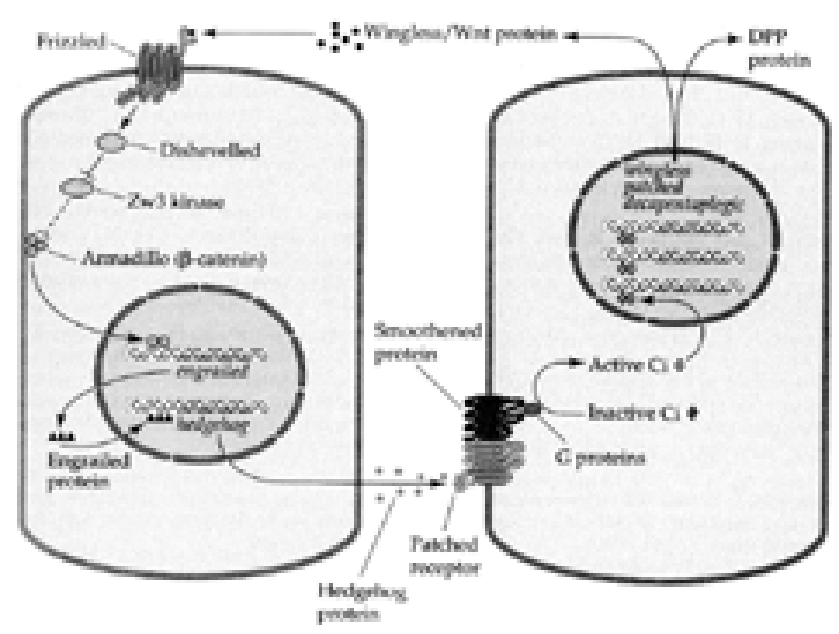

Fig. 10. Interactions of Sonic hedgehog and Wingless to establish metameric patterning between adjacent cells in Drosophila embryos. $\mathrm{Ci}=$ cubitus interruptus; $\mathrm{DPP}=$ decapentaplegia. 
just described. Transcription factors are soluble molecules including DNA sequences, RNA sequences, or peptides that interact with certain promoters or enhancers (sequences of DNA) to modulate transcription. Most transcription factors have both a DNA binding domain that binds with the promoter or enhancer region and other binding domains that interact with other DNA segments or regulators. There are various classes of transcription factors, including the POU transcription class (the initials in the acronym POU are taken from the first four proteins described with such domains: Pit-1, Oct-1, Oct-2, and Unc-86), the basic helix-loop-helix class, the basic leucine zipper class, the zinc finger class, the nuclear hormone receptor class, and the DNA bending class; each uses a different mechanism to control DNA transcription. One large class of transcription factors are the homeodomain proteins which, as will be explained, are extremely important during development. These proteins have a DNA binding region (the homeodomain) consisting of 60 amino acids arranged in a helix-turn-helix arrangement. The third helix in this arrangement extends into the major groove of the DNA at specific promoter sites, and other amino acids insert into the minor groove. Minor mutations (even a single amino acid substitution) can cause the homeodomain to recognize different promoters. The homeodomain proteins control the specification of metameric body patterning in all species from Drosophila to humans.

Induction of the Neuroepithelium. One overriding principle governing embryonic assembly is the process of embryonic induction, whereby a particular group of embryonic cells controls the developmental fate of an adjacent group of cells. From the standpoint of early nervous system development, the most important inductive interactions are the induction of neuroectoderm and the subsequent control of neurulation as well as the rostrocaudal segmentation of the neural tube into various regions and the metameric patterning of each. Each of these inductions involves the genetic control of cell fate in the responding tissues by signaling and transcription factors expressed by the inducing tissues.

As prospective endodermal and chordamesodermal (notochordal and prochordal plate) cells ingress through the Hensen node and come to underlie the epiblast, molecular interactions between these tissues induce the formation of the neuroepithelium. The molecular mechanisms underlying this remarkable induction have become known with the advent of molecular techniques. In avian embryos, the Hensen node expresses the homeodomain proteins goosecoid (and a related goosecoid protein, GSX), the homeodomain protein Otx2, HNF3 $\beta$, hepatocyte growth factor/scatter factor, and the CNOT proteins CNOT1 and CNOT2. Several other homeodomain proteins are also expressed somewhat later. In mouse embryo, the node expresses goosecoid, Lim1, Hnf3 $\beta$, and the secreted proteins noggin and nodal; follistatin is not expressed. These proteins are capable of inducing secondary neuraxes when added to indifferent regions of host embryos, and their misexpression in various mutants leads to deficiencies in the neuraxis. The ingressing chordamesoderm also expresses many factors. Sonic hedgehog is expressed sequentially within the developing notochord and the mid- line floorplate cells of the neural tube. As will be clarified, the expression of Sonic hedgehog is important for the development of the ventral neural tube, the sclerotome from the somite, and the spinal motorneurons. In addition, goosecoid and Otx2 are expressed in the prochordal plate mesoderm, and the protein CNOT1 in the notochord and tailbud.

The control of this inductive interaction to form the neuroepithelium is a fascinating event. It turns out that in the absence of any outside influence, isolated ectoderm will form neuroectoderm rather than epidermis. During normal development, this default pathway for ectoderm is inhibited by BMP-4 expressed both by ventral cells and by the early ectoderm itself, thus inhibiting neuronal differentiation and promoting cutaneous ectodermal differentiation. Factors secreted by the Hensen node and the chordamesoderm such as noggin, follistatin, and chordin, acting alone or in combination, suppress or antagonize the expression of BMP-4, and allow the ectoderm to follow its default pathway to form neuroectoderm (this has been previously reviewed ${ }^{33,35,54,62}$ ) This permissive interaction is repeated often during early development; cellular determination is controlled by inhibiting a factor(s) that would otherwise produce an alternative cell fate.

Primary Neurulation: Specification of the Notochord and Floorplate. The conformational change of MHP cells from a columnar to trapezoidal shape is controlled by inductive interactions between the notochord and the floor plate cells. ${ }^{50}$ Embryos in which the notochord is missing develop a neural tube but lack a floorplate; conversely, transplanting a second notochord to the lateral regions of the neural tube of a host embryo can induce an accessory floor plate. Expression of the homeodomain protein Sonic hedgehog from the notochord is the molecular substrate for the formation of the MHP; in addition, the expression of Sonic hedgehog from the notochord and/or the induced floorplate cells control the differentiation of ventral horn motoneurons. Mutants that lack notochordal Sonic hedgehog expression have neither a floorplate nor ventral horn motoneurons. Conversely, Sonic hedgehog induces secondary floor plate reactions and ectopic ventral horn motoneurons when placed adjacent to more lateral regions of the neural tube or in neural plate explants. In the mouse, loss of Sonic hedgehog expression in the head mesenchyme and rostral neural tube can result in holoprosencephaly ${ }^{29}$ and NTDs. ${ }^{23}$ Point mutations in the human Sonic hedgehog locus may be responsible for certain cases of familial holoprosencephaly. Sonic hedgehog is a signal transduction protein whose receptors include the transmembrane proteins patched and smoothened. Binding of Sonic hedgehog with patched produces a conformational change in smoothened that initiates an intracellular cascade involving the zinc finger protein cubitus interruptus, Costal, Suppresser of fused, threonine kinase fused, and the cAMP-dependent protein kinase A. The actions of Sonic hedgehog on the neuroectoderm are concentration dependent. High concentrations of Sonic hedgehog, or even direct contact between notochordal and neuroectodermal cells, is required to induce a floorplate response, whereas a lower concentration of Sonic hedgehog is required for ventral horn motorneuron differentiation. The type of ventral cell that is induced depends on its position 
along the rostrocaudal axis and is probably determined by interactions between Sonic hedgehog and other rostrocaudal patterning cues; at more caudal levels, Sonic hedgehog induces spinal cord motorneurons, whereas at midbrain and hindbrain levels ventrolateral dopaminergic and cholinergic cell types form. ${ }^{29}$

The dorsoventral differentiation of the neural tube seems to be established through competitive interactions between Sonic hedgehog (and perhaps also HNF-3 $\beta$ ) derived from the notochord, and other "dorsalizing factors" derived from the cutaneous ectoderm and dorsal part of the neural tube. Both the cutaneous ectoderm and the dorsal neural tube express a number of neural dorsalizing factors including BMP-4 and -7, Pax3, msx-1, and dorsalin-1, all of which, under experimental conditions, promote the differentiation of dorsal cell types from the neural tube.

The final event in primary neurulation is the medial convergence and fusion of the neural folds. Various observations suggest an important role for the homeobox gene Pax3 in this process. ${ }^{22}$ The geographic and temporal expression of Pax 3 in the dorsal neural tube precisely at the time of neural tube closure suggests that the Pax3 gene product might be important in neural fold fusion. Antisense oligonucleotides that block the function of Pax3 result in NTDs in mice. Moreover, the locus for the splotch mouse mutant, which exhibits NTDs (exencephaly and myelomeningocele), maps precisely to the Pax3 locus. Finally, the splotch mutant is the mouse homolog of the human Waardenburg syndrome Type I, in which myelomeningoceles have been reported in at least one family. ${ }^{9}$

\section{Rostrocaudal and Metameric Specification of the Neuraxis}

Results of transplantation experiments suggest that molecular species emitted from the Hensen node and/or its derivatives not only induce the neuroepithelium but also organize it along its rostrocaudal axis. According to this model, the interaction of two signals, one specifying a more rostral phenotype (forebrain, midbrain), and the second specifying more caudal structures (hindbrain, spinal cord), each expressed in different geographic patterns, could determine the craniocaudal pattern of the neuraxis. More recent molecular approaches seem to support this view; for example, noggin, chordin, follistatin, and Lim-1 can induce rostral but not caudal neural tissue, whereas other factors, such as retinoic acid and fibroblast growth factor, induce more caudal regions of the neuraxis.

The craniocaudal organization of the neuraxis (indeed of the whole body plan) is tightly controlled by a set of genes that are highly conserved across species. In Drosophila the progressive expression of craniocaudal patterning during development is controlled by a set of homeotic genes and their products. During normal Drosophila development, the body plan is determined by the craniocaudal gradients of four proteins derived from the mother: bicoid, hunchback, nanos, and caudal. The highest concentrations of hunchback and bicoid are rostral, whereas the highest concentrations of nanos and caudal are caudal. Therefore, there appear to be separate signals specifying rostral and caudal differentiation of the embryonic axis. ${ }^{23}$ The gradients of these four proteins set in motion the sequential expression of sets of embryonic gap genes, pair-rule genes, and segment polarity genes, each set resulting in a progressively greater craniocaudal segmentation of the Drosophila embryo. Within each segment, specific collections of transcription factors are expressed, all having in common a DNA binding segment called a homeodomain, which is encoded by a 180 -base pair region of the DNA called the homeobox gene. The homeodomain binds to the promoter regions of other genes on the DNA, directs the transcription of many other gene products, and establishes a craniocaudal pattern within each segment. Interactions between homeodomain proteins from adjacent segments establish and maintain the segmental pattern of the embryo. Homeotic mutants, mutants that misexpress certain homeodomain proteins in various segments, can have bizarre phenotypes; for example, the misexpression of the Antennapedia gene within the head segment leads to legs rather than eyes growing out of the head.

The mammallian homologs of the Drosophila homeotic genes are referred to as Homeobox, or Hox genes, and the transcription factors they encode control rostrocaudal patterning in higher vertebrates as well. For example, the homeobox genes Lim 1 and Otx2 appear to be important in organizing head regions of the embryo; a knockout mutation of either of these genes produces mice lacking all neuraxial structures rostral to the otic vesicles but possessing normal trunk structures. The siamois gene may also play a role in rostral neural development; overexpression of siamois in Xenopus embryos results in the duplication of rostral neuraxial structures. Another homeobox gene, cerberus, seems specifically to induce forebrain regions. Other homeobox genes likely control more caudal neuraxial development but have not yet been characterized.

The earliest expression of these genes determines patterning in a broader sense such as the division of the neuraxis into prosencephalon, the mesencephalon-metencephalon border (mes-met), and the myelencephalon, each having a distinct pattern of genetic expression. Later, the expression of various homeobox genes controls the metameric segmentation within each segment. The metameric segmentation of the rhombencephalon into its constituent rhombomeres has been particularly well studied. Various homeobox genes have been mapped to this region, and the boundaries of expression of various genes coincides with the boundaries of the rhombomeres, with a two rhombomere periodicity. The pattern and distribution of these various homeobox genes may determine the regional characteristics of each rhombomere, although these interrelationships are complicated and not entirely worked out. The expression of the homeobox genes of the rhombencephalon are themselves controlled by other homeobox genes such as Krox-20, kriesler, and c-maf. Metameric patterning in other segments of the neuraxis, including the spinal cord, is not as well established, but is likely to be similarly controlled by homeobox genes.

\section{EMBRYOGENESIS OF HUMAN MYELOMENINGOCELES}

There are two fundamental theories regarding the embryogenesis of myelomeningocele, both encompassing a 
disorder of primary neurulation. In the so-called nonclosure theory initially suggested by von Recklinghausen, it is proposed that neural tube defects represent a primary failure of neural tube closure. In the overdistension theory, introduced in 1769 by Morgagni and popularized by Gardner, it is proposed that NTDs arise through overdistension and rupture of a previously closed neural tube. The nonclosure theory is more widely accepted and certainly accounts for the majority of human NTDs; however, overdistension may contribute to some experimental neural tube defect models, particularly those caused by vitamin $\mathrm{A}^{7}$ and the T-curtailed mouse mutant. ${ }^{11}$

In addition to the traditional view of NTDs as disorders of neurulation, Dias and Pang ${ }^{15}$ and Dias and Walk$\mathrm{er}^{17}$ have more recently proposed that a number of myelomeningoceles (particularly some cervicothoracic myelomeningoceles, hemimyelomeningoceles, and those myelomeningoceles associated with SCMs (diastematomyelia) and other complex dysraphic malformations) arise not as a result of a primary failure of neurulation, but as a result of disordered midline axial integration during gastrulation. The primary embryonic abnormality for these malformations, according to this theory, is the failure of the Hensen node to lay down properly a single notochord flanked by a cohesive surrounding sheet of neuroepithelium. Instead, paired notochordal anlagen develop from each half of the Hensen node during gastrulation and two relatively independent hemineural plates, each developing into a hemicord, arise on either side of the node (Fig. 11). The malformations so induced may secondarily disrupt neurulation and result in either a hemimyelomeningocele (if neurulation fails in only one hemicord) or a myelomeningocele associated with an SCM rostral or caudal to the placode (if primary neurulation fails in both hemicords). Multipotent cells contained within the Hensen node and laid down between the two hemicords may form various normal and abnormal tissue types (such as ovarian and renal tissues, Wilm tumor, or teratoma) and result in a wide variety of malformations such as neurenteric cysts, combined spina bifida (split notochord syndrome), and other entities. ${ }^{17}$ Experimental manipulations of the Hensen node in chick embryos can produce malformations that resemble human SCMs and provide some experimental support for such a mechanism. ${ }^{17}$

Because early neural embryogenesis in general, and neurulation in particular involve a complex interplay of multiple cellular processes, tissue morphogenesis, and the timely expression of multiple transcription and cell signaling factors, it is not surprising that NTDs may result from a number of embryonic insults. Neural tube defects have been produced experimentally using a number of teratogens, ${ }^{8}$ genetic mutations,,${ }^{10,11,31}$ and experimental manipulations. ${ }^{50}$ Although these all suggest a number of potential mechanisms whereby NTDs might arise, the cause of human malformations remains unknown. Neural tube defects are most likely heterogeneous in origin ${ }^{8,10,11,17}$ and represent the end result of a various embryonic disorders.

What is clear, however, is that NTDs represent the intricate interactions between complex genetic and environmental factors. Many lines of evidence point to a genetic component for NTDs. First and most obvious, the incidence of NTDs increases in first-degree relatives of pa-

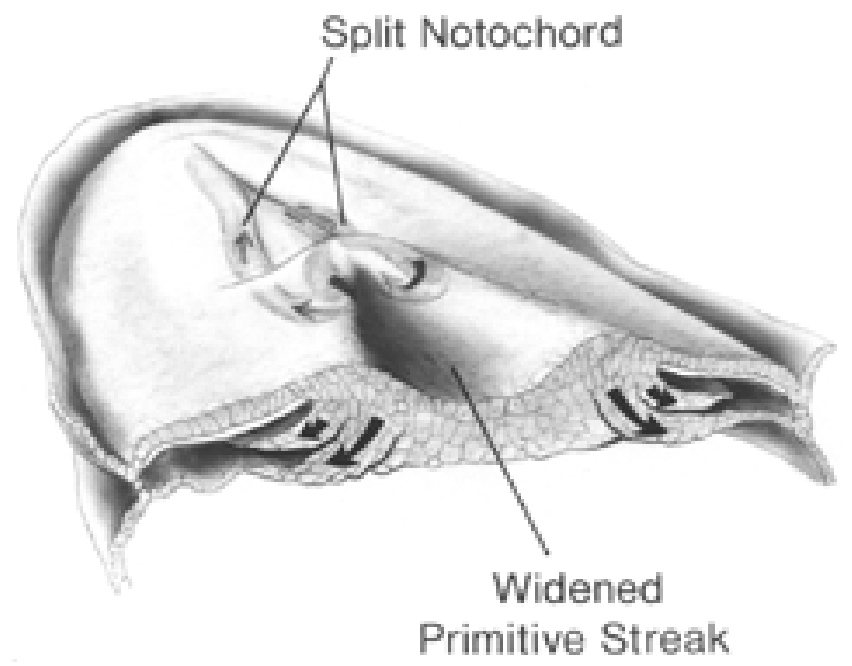

Fig. 11. Embryogenetic theory for the origin of some myelomeningoceles, hemimyelomeningoceles, SCMs, and other complex dysraphic malformations. According to this theory, the Hensen node is altered resulting in disrupted midline axial integration during gastrulation. Two heminotochords are laid down and the surrounding neural plate is induced to form two relatively independent hemineural tubes. The intervening cells derived from multipotent cells in the Hensen node can develop into a variety of both normal and abnormal tissues between the two resultant hemicords such as neurenteric cysts, ectopic ovarian or renal tissues, Wilm tumor or teratomas (all reported in the literature). From Luo and Nye, 2001.

tients with these defects. For example, the risk of the parents of a child with an NTD giving birth to a second child with an NTD is 2 to 3\%; after having two children with NTDs, the risk of a third child with an NTD rises to $10 \%$ or more. ${ }^{36}$ Second, the incidence of NTDs varies widely between different populations, even after accounting for geographic migration and other factors. Third, concordance rates between monozygotic twin pairs vary between 3.7 and $18 \% .{ }^{39}$ Fourth, NTDs are seen in association with known genetic syndromes (such as Waardenberg syndrome) and chromosomal anomalies (such as trisomy 13 and 18). There are also families in whom Mendelian inheritance is documented (one dominant and the other recessive). Finally, chromosomal rearrangements such as aneuploidy have been reported.

Genetic models of NTDs provide a means of identifying particular gene(s) that might be involved in neural tube closure. ${ }^{10,11,31}$ To date, more than 60 genetic mouse mutants with NTDs have been identified. ${ }^{31}$ These mutations code for a bewildering variety of molecular species including various transcription factors and coactivators, signal transducers, folate binding proteins, tumor suppressor gene products, cytoskeletal components, DNA methyltransferases, nuclear and cell membrane receptors, chromosomal proteins, gap junction proteins, cell surface receptors, and actin regulators and binding proteins. ${ }^{31}$ Many mutants exhibit specific types of NTDs involving disruption of specific waves of neural tube closure and suggest that each wave has specific and discrete elements that contribute to closure and which can be disrupted without interfering with other waves. The looptail mouse 
mutant, for example, results in disruption of only spinal neurulation without producing a cranial NTD; the mutation causes abnormally broad misexpressions of Sonic hedgehog, Netrin1, and Brachyury. Other mutations appear to disrupt more than one wave of closure suggesting that there may be common pathways as well. ${ }^{31}$

Three examples illustrate the varied ways in which genetic mutations can result in an NTD. The splotch mouse mutants are identified by a peculiar patch of white fur and exhibit both exencephaly and myelomeningoceles. The genetic locus for the splotch mutation is within the Pax-3 gene (as previously discussed), a transcription factor that may be involved in neural fold fusion; how Pax-3 mutation causes NTDs is largely unknown. A second mouse mutant, curly tail, exhibits posterior NTDs and tail deformities associated with a delay in the closure of the caudal neuropore. The delay, however, is not the result of faulty neuroepithelial development, because isolated neuroepithelium from curly tail mutants undergoes normal neurulation. Rather, there is a delay in cell proliferation in the underlying notochord and hindgut endoderm that, in turn, causes an abnormal anterior curvature to the body axis and impedes posterior neuropore closure. ${ }^{10,11}$ If the anterior curvature is corrected by splinting the caudal curly tail embryo with an eyelash or by retarding neuroepithelial proliferation by using retinoic acid; the posterior neuropore closes normally and the incidence of NTDs is reduced. More recent evidence points to a deficiency in Wnt5a, RAR $\beta$, and RAR $\gamma$ gene expression. ${ }^{20} \mathrm{~A}$ third mouse mutant, T-curtailed produces a lumbosacral myelomeningocele with dorsoventral forking of the caudal neural tube. Rather than delayed or failed neural tube closure, however, the $T$-curtailed mutant causes rupture of the roof plate and re-opening of a previously closed neural tube. ${ }^{11}$ Each of these mouse mutants exhibits an NTD that arises via a wholly different mechanism.

Although responsible for many different mouse animal models of NTDs, whether any of these mutations is responsible for human NTDs is largely unknown. The frustration of trying to isolate candidate genes that are causal in humans is demonstrated by the work of the Neural Tube Defect Collaborative Group whose investigators have undertaken a detailed genetic analysis of patients with myelomeningoceles and their families; they have screened blood samples obtained in a large number of cases for various genetic mutations. These analyses have been more helpful in determining what genes are not involved in human NTDs rather than in finding candidate gene(s). For example, neither the folate uptake genes $F R \alpha$ or $F R \beta$, the BMP antagonist noggin, Pax-3, p53, nor the t-locus (brachyury) appear to be involved in the genesis of human NTDs. ${ }^{3,39,45,55}$

Particular interest has recently focused on genes that control folate metabolism and methyltransferase reactions involving methionine and homocysteine; this approach also provides an opportunity to examine the interactions of both genetic and environmental factors. The role of nutrition in the embryogenesis of NTDs was brought to light very early by a simple observation made by a Dutch midwife that the incidence of NTDs rose in 1722 and 1732 during which there were very poor crop yields in Holland. The incidence again rose abruptly following the so-called
Hunger Winter of 1944 to 1945 in the Netherlands. ${ }^{65}$ Various studies conducted by Hibbard and Smithels and colleagues in the 1960s and 1970s noting reduced levels of red blood cell folate in mothers of offspring with NTDs spurred research to examine the role of folate in the embryogenesis of NTDs. Maternal administration of folate antagonists such as aminopterin had long been known to produce NTDs. ${ }^{52}$ Periconceptional administration of supplemental folate in randomized placebo-controlled studies was shown to reduce the recurrence rate of NTDs among both women with a previously affected pregnancy and the incidence among women who had never had an affected pregnancy. ${ }^{12,42}$ Studies of maternal serum and red blood cell folate levels among mothers of infants with myelomeningocele, however, have produced inconsistent results, ${ }^{53,66}$ and folate deficiency does not cause NTDs in mice or rat embryos. ${ }^{21}$ These observations suggest that NTDs are rarely the result of an isolated absolute folate deficiency.

More recent attention has focused on the possibility that NTDs are caused by abnormalities involving metabolic pathways (in the mother or fetus) that require folate; ${ }^{51}$ these would be abnormalities that predispose an individual to NTDs and might therefore be overcome by folate supplementation. A thorough discussion of this area is well beyond the reach of this paper, and the interested reader is referred to an excellent recent monograph by van der Put and colleagues. ${ }^{65}$ Folate is a vitamin absorbed in the jejunum as 5-methyltetrahydrofolate monoglutamate. The transport of 5-methyltetrahydrofolate is moderated both by carrier- and receptor-mediated mechanisms. Receptors for folate are membrane bound and include four isoforms: FR $\alpha, F R \beta, F R \gamma$, and FR' $\gamma$. Unfortunately, neither FR $\alpha$ nor FR $\beta$ occurs with increased frequency in mothers or offspring having NTDs.

Folate and its metabolites (particularly tetrahydrofolate and 5-methyltetrahydrofolate) are vital for various mammallian metabolic reactions, including purine and pyrimidine (and therefore DNA) synthesis, and in the transfer of methyl groups during the metabolism of methionine and homocysteine (Fig. 12). In particular, the role of folate in methionine and homocysteine metabolism has generated considerable interest recently. ${ }^{5,6,27,40,47,57,59,63,67}$ The metabolism of homocysteine follows one of two pathways. One involves a transsulphuration to cystathionine, catalyzed by the enzyme cystathionine synthase; cystothianine is subsequently converted to cysteine. The second metabolic pathway for homocysteine is the remethylation of homocysteine to methionine, catalyzed by the enzyme methionine synthase and requiring the donation of a methyl group from the folate metabolite 5-methyltetrahydrofolate (which, in turn, is converted to tetrahydrofolate), using vitamin B12 as a cofactor. Methionine is activated by adenosine $5^{\prime}$-triphosphate to produce S-adenosylmethionine, a high-energy compound that donates methyl groups for over 100 cellular methyltransferase reactions involving protein, lipid, DNA, and RNA metabolism. This critical reaction is controlled by methionine synthase that in turn is controlled by the soluble cytochrome b5 and methionine synthase reductase. Tetrahydrofolate is converted back to 5-methyltetrahydrofolate by the enzyme 5,10-methylenetetrahydrofolate reductase (Fig. 12). 


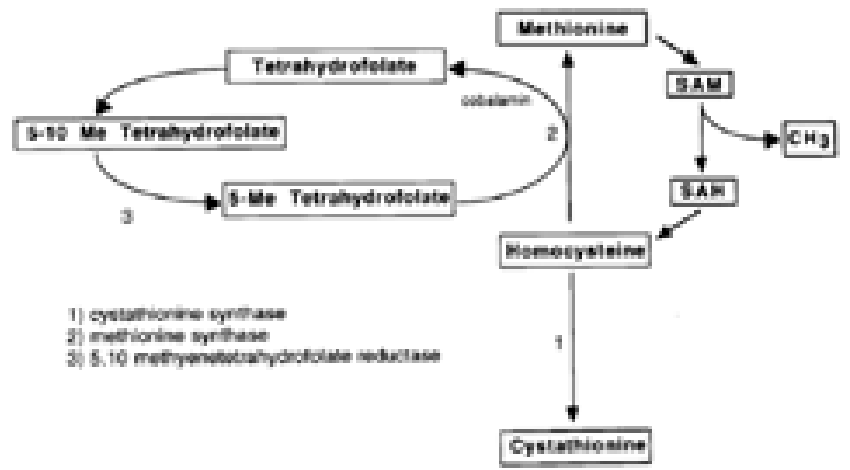

Fig. 12. The homocysteine/methionine cycle. The conversion of homocysteine to methionine is mediated by the donation of a methyl group from 5-methyltetrahydrofolate (5-Me tetrahydrofolate); in the process, tetrahydrofolate is formed. This reaction is catalyzed by the enzyme methionine synthase and uses cobalamin (vitamin B12) as a coenzyme. The 5-methyletrahydrofolate is regenerated from tetrahydrofolate by using 5,10-methylenetetrahydrofolate (5-10 Me Tetrahydrofolate) as an intermediary, completing a folate cycle. Methionine is subsequently used as a methyl $(\mathrm{CH} 3)$ donor in various important metabolic reactions and is converted to homocysteine in the process. $\mathrm{SAH}=\mathrm{S}$-adenosylhomocysteine; $\mathrm{SAM}=\mathrm{S}$-adenosylmethionine .

There are therefore a large number of potential candidate genes that code either for enzymes involved in the methylation cycle or gene products that control it, and considerable research has focused on identifying which of these might be responsible for the embryogenesis of NTDs. One hypothesis is that maternal or fetal mutations in either methionine synthase or 5,10-methylenetetrahydrofolate reductase may slow down this methylation cycle, drive the conversion of methionine to homocysteine, and lead to methionine deficiency and/or homocysteine excess. Ingestion of higher doses of folate may overcome this relative deficiency by restoring more normal homocysteine and methionine levels. ${ }^{51,57,58}$ Numerous observations support this view. For example, elevated maternal homocysteine levels have been identified in women carrying a fetus that harbors an NTD, both in serum ${ }^{40}$ and in amnionic fluid. ${ }^{57}$ Disordered methionine metabolism has been demonstrated in nonpregnant women who previously had given birth to a child with an NTD. ${ }^{57,58}$ Methionine supplementation can reduce the risk of NTDs in rats and possibly in humans. ${ }^{65}$ Finally, polymorphisms involving the 5,10-methylenetetrahydrofolate reductase gene have been demonstrated in one study in $18 \%$ of individuals with NTDs, and in $13 \%$ of parents of children with NTDs, compared with $6 \%$ in controls. ${ }^{28,67}$ The risks of NTD are additive if both mother and fetus are homozygous for an methylenetetrahydrofolate polymorphism. ${ }^{65}$ Other authors have failed to find evidence of such polymorphism. ${ }^{39}$ Moreover, there is no specific pattern of genetic polymorphisms that appears to be consistently responsible for the embryogenesis of even a majority of NTDs. Given the complexities of the methylation cycle and the many enzymatic controls, it may be that NTDs reflect complex interactions between multiple enzyme systems that, with the proper combination of polymorphisms in either mother or fetus, result in failure of neural tube closure.
A number of teratogens are known to act through various cellular mechanisms to cause NTDs in animals and/ or humans. ${ }^{11}$ One important teratogen, valproic acid, produces NTDs in both animal models and in humans, probably by inhibiting neural fold fusion. ${ }^{11}$ Although the exact mechanism is not known, valproic acid appears to disrupt folate metabolic pathways, perhaps by interfering with the conversion of tetrahydrofolate to 5-formyltetrahydrofolate. ${ }^{57}$ Maternal folate administration reduces the incidence of valproic acid-associated NTDs in some, but not all, studies, and mouse strains that are susceptible to valproate acid-induced NTDs have significantly lower levels of 5,10-methylenetetrahydrofolate following valproic acid administration compared with resistant strains. In addition, a number of developmental regulatory genes (such as transcription factors and cell cycle checkpoint genes) may be altered in these susceptible strains. One hypothesis is that valproic acid may act by changing folate-dependent methylation of regulatory proteins such as transcription factors.

Finally, as many as 30 to $50 \%$ of NTDs appear to be caused by factors that are not responsive to folate administration and likely involve folate-independent mechanisms. Given the heterogeneity of factors that can potentially disrupt the developing neural tube, it is unlikely that a single agent will explain the embryogenesis of myelomeningocele.

\section{CONCLUSIONS}

In conclusion, despite an explosion of knowledge into both the morphogenetic and biochemical underpinnings of normal neural tube closure, the discovery of numerous genetic models of NTDs, and a much clearer understanding of the complexities of folate and its biochemical pathways, the exact mechanism by which each of these factors interacts in complex ways to produce a human myelomeningocele remains a mystery.

\section{References}

1. Barson AJ: Spina bifida: the significance of the level and extent of the defect to the morphogenesis. Dev Med Child Neurol 12: 129-144, 1970

2. Barson AJ: The vertebral level of termination of the spinal cord during normal and abnormal development. J Anat 106: 489-497, 1970

3. Bauer KA, George TM, Enterline DS, et al: A novel mutation in the gene encoding noggin is not causative in human neural tube defects. J Neurogenet 16:65-71, 2002

4. Bolli P: Sekundäre Lumenbildungen im Neuralrohr und Rückenmark menschlicher Embryonen. Acta Anat 64:48-81, 1966

5. Bower C: Folate and neural tube defects. Nutr Rev 53: S33-S38, 1995

6. Buehler JW, Mulinare J: Preventing neural tube defects. Pediatr Ann 26:535-539, 1997

7. Caldarelli M, McLone DG, Collins JA, et al: Vitamin A induced neural tube defects in the mouse. Concepts Pediatr Neurosurg 6:161-171, 1985

8. Campbell LR, Dayton DH, Sohal GS: Neural tube defects: a review of human and animal studies on the etiology of neural tube defects. Teratology 34:171-187, 1986

9. Chatkupt S, Chatkupt S, Johnson WG: Waardenburg syndrome and myelomeningocele in a family. J Med Genet 30:83-84, 1993 
10. Copp AJ: Genetic models of mammalian neural tube defects, in Bock G, Marsh J (eds): Neural Tube Defects. CIBA Foundation Symposium, Number 181. Chichester, UK: John Wiley \& Sons, 1994, pp 118-143

11. Copp AJ, Brook FA, Estibeiro P, et al: The embryonic development of mammalian neural tube defects. Prog Neurobiol 35: 363-403, 1990

12. Czeizel AE, Dudás I: Prevention of the first occurrence of neural-tube defects by periconceptional vitamin supplementation. N Engl J Med 327:1832-1835, 1992

13. Dias MS, McLone DG: Normal and abnormal early development of the nervous system, in McLone DG (ed): Pediatric Neurosurgery: Surgery of the Developing Nervous System, ed 4. Philadelphia: WB Saunders, 2001, pp 31-71

14. Dias MS, McLone DG, Partington M: Normal and abnormal embryology of the spinal cord and spine, in Winn HR (ed): Youmans Neurological Surgery, ed 5. Philadelphia: WB Saunders, 2003, Vol 4, pp 4239-4288

15. Dias MS, Pang D: Split cord malformations. Neurosurg Clin $\mathbf{N}$ Am 6:339-358, 1995

16. Dias MS, Schoenwolf GC: Molecular biology of early neural development, in McLone DG (ed): Pediatric Neurosurgery: Surgery of the Developing Nervous System, ed 4. Philadelphia: WB Saunders, 2001, pp 73-86

17. Dias MS, Walker ML: The embryogenesis of complex dysraphic malformations: a disorder of gastrulation? Pediatr Neurosurg 18:229-253, 1992

18. DiPietro MA: The conus medullaris: normal US findings throughout childhood. Radiology 188:149-153, 1993

19. Edelman GM: Surface modulation in cell recognition and cell growth. Science 192:218-226, 1976

20. Finnell RH, Gould A, Spiegelstein O: Pathobiology and genetics of neural tube defects. Epilepsia 44 (Suppl 3):14-23, 2003

21. Fleming A, Copp AJ: Embryonic folate metabolism and mouse neural tube defects. Science 280:2107-2109, 1998

22. George TM, McLone DG: Mechanisms of mutant genes in spina bifida: a review of implications from animal models. Pediatr Neurosurg 23:236-245, 1995

23. Gilbert SF: Developmental Biology, ed 5. Sunderland, MA: Sinauer Associates, 1997

24. Gilbert SF: Developmental Biology, ed 7. Sunderland, MA: Sinauer Associates, 2003

25. Golden JA, Chernoff GF: Intermittent pattern of neural tube closure in two strains of mice. Teratology 47:73-80, 1993

26. Golden JA, Chernoff GF: Multiple sites of anterior neural tube closure in humans: evidence from anterior neural tube defects (anencephaly). Pediatrics 95:506-510, 1995

27. Gordon N: Folate metabolism and neural tube defects. Brain Dev 17:307-311, 1995

28. Goyette P, Sumner JS, Milos R, et al: Human methylenetetrahydrofolate reductase: isolation of cDNA, mapping and mutation identification. Nat Genet 7:195-200, 1994

29. Hammerschmidt M, Brook A, McMahon AP: The world according to hedgehog. Trends Genet 13:14-21, 1997

30. James CCM, Lassman LP: Spinal Dysraphism: Spina Bifida Occulta. London: Butterworth, 1972

31. Juriloff DM, Harris MJ: Mouse models for neural tube closure defects. Human Mol Genet 9:993-1000, 2000

32. Kaufman MH: Occlusion of the neural lumen in early mouse embryos analysed by light and electron microscopy. J Embryol Exp Morphol 78:211-228, 1983

33. Kelly OG, Melton DA: Induction and patterning of the vertebrate nervous system. Trends Genet 11:273-278, 1995

34. Lemire RJ: Secondary caudal neural tube formation, in Lemire RJ, Loeser JD, Leech RW, et al (eds): Normal and Abnormal Development of the Human Nervous System. Hagerstown, MD: Harper \& Row, 1975, pp 71-83

35. Lumsden A, Krumlauf R: Patterning the vertebrate neuraxis. Science 274:1109-1115, 1996
36. Luo J, Nye JS: Evidence for genetic etiologies of neural tube defects, in Sarwark JF, Lubicky JP (eds): Caring for the Child with Spina Bifida. Rosemont, IL: American Academy of Orthopaedic Surgeons, 2001, pp 43-62

37. McLone DG, Knepper PA: The cause of Chiari II malformation: a unified theory. Pediatr Neurosurg 15:1-12, 1989

38. McLone DG, Knepper PA: Role of complex carbohydrates and neurulation. Pediatr Neurosci 12:2-9, 1985/1986

39. Melvin EC, George TM, Worley G, et al: Genetic studies in neural tube defects. NTD Collaborative Group. Pediatr Neurosurg 32:1-9, 2000

40. Minns RA: Folic acid and neural tube defects. Spinal Cord 34: 460-465, 1996

41. Moore KL: The Developing Human: Clinically Oriented Embryology, ed 3. Philadelphia: WB Saunders, 1982

42. MRC Vitamin Study Research Group: Prevention of neural tube defects: results of the Medical Research Council Vitamin Study. Lancet 338:131-137, 1991

43. Müller F, O'Rahilly R: The development of the human brain, the closure of the caudal neuropore, and the beginning of secondary neurulation at stage 12. Anat Embryol 176:413-430, 1987

44. Müller F, O'Rahilly R: Somitic-vertebral correlation and vertebral levels in the human embryo. Am J Anat 177:3-19, 1986

45. Rampersaud E, Melvin EC, Siegel D, et al: Updated investigations of the role of methylenetetrahydrofolate reductase in human neural tube defects. Clin Genet 63:210-214, 2003

46. Reimann AF, Anson BJ: Vertebral level of termination of the spinal cord with report of a case of sacral cord. Anat Rec 88: 127-138, 1944

47. Rosenquist TH, Ratashak SA, Selhub J: Homocysteine induces congenital defects of the heart and neural tube: effect of folic acid. Proc Natl Acad Sci USA 93:15227-15232, 1996

48. Schoenwolf GC, Desmond ME: Timing and positioning of reopening of the occluded spinal neurocele in the chick embryo. J Comp Neurol 246:459-466, 1986

49. Schoenwolf GC, Sheard P: Fate mapping the avian epiblast with focal injections of a fluorescent-histochemical marker: ectodermal derivatives. J Exp Zool 255:323-339, 1990

50. Schoenwolf GC, Smith JL: Mechanisms of neurulation: traditional viewpoint and recent advances. Development 109: 243-270, 1990

51. Scott JM, Weir DG, Molloy A, et al: Folic acid metabolism and mechanisms of neural tube defects, in Bock G, Marsh J (eds): Neural Tube Defects. CIBA Foundation Symposium, Number 181. Chichester, UK: John Wiley \& Sons, 1994, pp 180-191

52. Seller MJ: Maternal nutrition factors and neural tube defects in experimental animals, in Dobbing J (ed): Prevention of Spina Bifida and Other Neural Tube Defects. New York: Academic Press, 1983, pp 1-22

53. Seller MJ: Vitamins, folic acid and the cause and prevention of neural tube defects, in Bock G, Marsh J (eds): Neural Tube Defects. CIBA Foundation Symposium Number 181. Chichester, UK: John Wiley \& Sons, 1994, pp 161-179

54. Smith JL, Schoenwolf GC: Getting organized: new insights into the organizer of higher vertebrates. Curr Top Dev Biol 40: 79-110, 1998

55. Speer MC, Melvin EC, Viles KD, et al: T locus shows no evidence for linkage disequilibrium or mutation in American Caucasian neural tube defect families. Am J Med Genet 110: 215-218, 2002

56. Spratt NT Jr: Regression and shortening of the primitive streak in the explanted chick blastoderm. J Exp Zool 104:69-100, 1947

57. Steegers-Theunissen RP: Folate metabolism and neural tube defects: a review. Eur J Obstet Gynecol Reprod Biol 61:39-48, 1995

58. Steegers-Theunissen RPM, Boers GHJ, Trijbels FJM, et al: 
Maternal hyperhomocysteinemia: a risk factor for neural-tube defects? Metabolism 43:1475-1480, 1994

59. Steegers-Theunissen RPM, Boers GHJ, Trijbels FJM, et al: Neural-tube defects and derangement of homocysteine metabolism. New Engl J Med 324:199-200, 1991

60. Tam PPL, Behringer RR: Mouse gastrulation: the formation of a mammalian body plan. Mech Dev 68:3-25, 1997

61. Tan SS, Morriss-Kay G: The development and distribution of the cranial neural crest in the rat embryo. Cell Tissue Res 240: 403-416, 1985

62. Tanabe Y, Jessell TM: Diversity and pattern in the developing spinal cord. Science 274:1115-1123, 1996

63. Ubbink JB: Is an elevated circulating maternal homocysteine concentration a risk factor for neural tube defects? Nutr Rev 53:173-175, 1995

64. Van Allen MI, Kalousek DK, Chernoff GF, et al: Evidence for multi-site closure of the neural tube in humans. Am J Med Genet 47:723-743, 1993

65. van der Put NMJ, van Straaten HWM, Trijbels FJM, et al: Folate, homocysteine and neural tube defects: an overview. Exp Biol Med 226:243-270, 2001
66. Wald NJ: Folic acid and neural tube defects: the current evidence and implications for prevention, in Bock G, Marsh $\mathrm{J}$ (eds): Neural Tube Defects. CIBA Foundation Symposium, Number 181. Chichester, UK: John Wiley \& Sons, 1994, pp 192-211

67. Whitehead AS, Gallagher P, Mills JL, et al: A genetic defect in 5,10 methylenetetrahydrofolate reductase in neural tube defects. QJM 88:763-766, 1995

68. Wilson DA, Prince JR: John Caffrey award. MR imaging determination of the location of the normal conus medullaris throughout childhood. AJR 152:1029-1032, 1989

69. Wolf S, Schneble F, Tröger J: The conus medullaris: time of ascendence to normal level. Pediatr Radiol 22:590-592, 1992

Manuscript received December 15, 2003.

Accepted in final form January 19, 2004.

Address reprint requests to: Mark S. Dias, M.D., Department of Neurological Surgery H110, Penn State Milton S. Hershey Medical Center, 500 University Drive, Penn State University College of Medicine, Hershey, Pennsylvania 17033. email: mdias@psu.edu. 